\title{
COVID-19: LAS MÚLTIPLES VULNERABILIDADES DEL SECTOR EXTERNO DE AMÉRICA LATINA Y EL CARIBE FRENTE A LA CRISIS SANITARIA ${ }^{\circ}$
}

\author{
COVID-19: THE MULTIPLE VULNERABILITIES OF THE \\ EXTERNAL SECTOR IN LATIN AMERICA AND THE CARIBBEAN \\ IN THE FACE OF THE HEALTH CRISIS
}

Kathia Michalczewsky*

enviado: 07 abril 2020 - aceptado: 13 abril 2020

\begin{abstract}
Resumen
Esta nota de análisis pretende dar un panorama sobre los canales de transmisión del impacto económico de la crisis sanitaria provocada por la pandemia del COVID-19 a los flujos comerciales de América Latina y el Caribe. Se examinan tres vías de contagio: la demanda, los términos de intercambio y la oferta, identificando los niveles de vulnerabilidad de la región en cada uno. Finalmente, se analizan las políticas comerciales que se han aplicado como respuesta a la crisis sanitaria tanto en los países de América Latina y el Caribe como en el resto del mundo, pero que podrían afectar a la región.
\end{abstract}

Código JEL: F14, F42, I18.

Palabras clave: COVID-19, coronavirus, comercio internacional, América Latina y el Caribe, términos de intercambio, política comercial.

\footnotetext{
- Michalczewsky, K. (2020). COVID-19: las múltiples vulnerabilidades del sector externo de América Latina y el Caribe frente a la crisis sanitaria. Estudios económicos, 37 (74), 191-204.

$\wedge$ Esta nota fue realizada con base en publicaciones previas en las que colaboró la autora: BID-INTAL (2020a y 2020b) y Giordano (2020).

* Consultora BID-INTAL. Correo electrónico: kmichalczewsky@gmail.com
} 


\begin{abstract}
This article aims to provide an overview of the transmission channels of the economic impact of the health crisis caused by the COVID-19 pandemic to Latin America and the Caribbean external trade. Three channels of commercial contagion are examined: demand, terms of trade and supply, identifying the levels of vulnerability of the region in each one. Finally, an analysis is made of the trade policies that have been applied in response to the health crisis both in the countries of Latin America and the Caribbean and in the rest of the world which could affect the region.
\end{abstract}

JEL Code: F14, F42, I18.

Key words: COVID-19, coronavirus, international trade, Latin America and the Caribbean, terms of trade, trade policy. 


\section{INTRODUCCIÓN}

Desde el estallido de la crisis sanitaria global provocada por el COVID-19 se están realizando múltiples esfuerzos para medir el impacto que tendrá sobre la economía mundial y buscar políticas para minimizarlo. Aunque tener una respuesta precisa resulta inalcanzable, conocer cuáles son los canales de transmisión y las principales vulnerabilidades permite entender el fenómeno y diseñar medidas para contenerlo. El shock económico se genera por tres vías principales: comercio internacional, el canal financiero y el mercado interno. Esta nota de análisis se centra en el canal comercial, y más específicamente, en el rol que cumplirá en el contagio económico de América Latina y el Caribe.

Se debe considerar que la crisis sanitaria llega en un momento donde tanto la economía global como los flujos de intercambio se encuentran debilitados. El volumen del comercio mundial se contrajo en 2019 por primera vez desde la Gran Recesión de 2009, luego de acumular una década de bajo crecimiento. Los registros preliminares para el mes de enero de 2020 muestran una contracción interanual de $2.0 \%$, cuando aún la crisis sanitaria era incipiente. Considerando el rezago de publicación de los datos de comercio, el impacto inmediato se puede estimar observando algunos indicadores adelantados como el componente de nuevos pedidos de exportación del Î́ndice de Compras de Gerentes que indica el empeoramiento (mejoramiento) de las condiciones si se encuentra por debajo (encima) de 50. Este subíndice, que ya se encontraba en niveles inferiores a 50 desde septiembre de 2018, se redujo a 44.9 en febrero y a 43.3 en marzo (gráfico 1), mínimos solo comparables con los alcanzados durante la crisis financiera de 2008-2009. A modo de comparación, a inicios de 2009, el subíndice se ubicó en un nivel cercano a 30, y los meses siguientes el volumen del comercio mundial se contrajo alrededor de $18 \%$ interanual ${ }^{1}$.

Sin embargo, la comparación tanto con otras crisis económicas como con otras epidemias debe considerar que el contexto ha cambiado notablemente: por un lado, la economía global se encuentra mucho más integrada tanto en términos de movilidad de personas como de bienes y factores, así como financieramente. Por lo tanto, así como se considera que este virus es relativamente más contagioso que otros, también se estima que lo sean los efectos económicos. Por otro lado, como ya se mencionó, en comparación con la crisis financiera más reciente la actividad económica y el comercio mundial ya se encontraban en una situación de fragilidad antes del estallido de la pandemia. En particular las economías en desarrollo, entre

1 Williamson (2019). 
ellas, las de América Latina y el Caribe se encuentran en una situación de mayor vulnerabilidad, y por lo tanto los efectos negativos serán más profundos.

Gráfico 1. Nuevos pedidos de exportación y volumen del comercio mundial. Índices y tasa de variación interanual

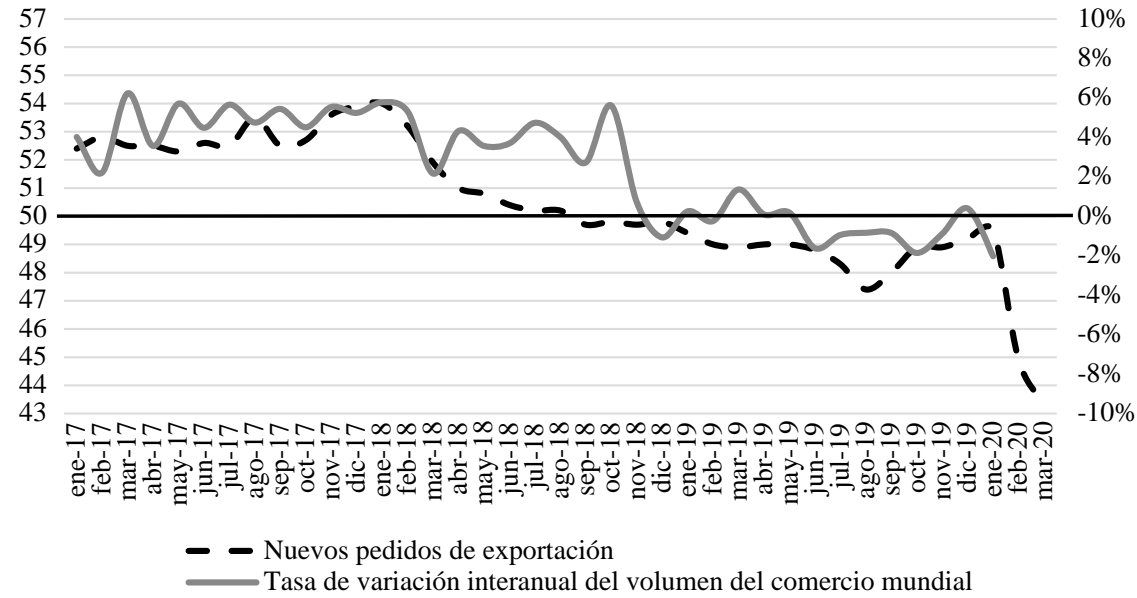

Fuente: elaboración propia con datos de IHS Markit y CPB Netherlands.

\section{LOS CANALES DE TRANSMISIÓN DEL IMPACTO COMERCIAL}

Los efectos de la crisis sanitaria afectarán al sector externo de América Latina y el Caribe por varias vías: la contracción de la demanda por la menor actividad económica, los términos de intercambio, por la alta volatilidad en los precios de los productos básicos y el recorte de la oferta por los problemas logísticos y de abastecimiento.

En cuanto a la demanda, se debe considerar que las economías con mayor número de contagiados hasta el momento no solo son las más grandes a nivel global, sino también son los principales socios comerciales de América Latina y el Caribe (ALC): China, la Unión Europea (UE) y Estados Unidos (EE. UU.). En conjunto estos tres destinos representaron dos tercios de las exportaciones totales de la región en 2018 (gráfico 2). 
Gráfico 2. Principales socios comerciales de ALC. Participación en el total de exportaciones, 2018

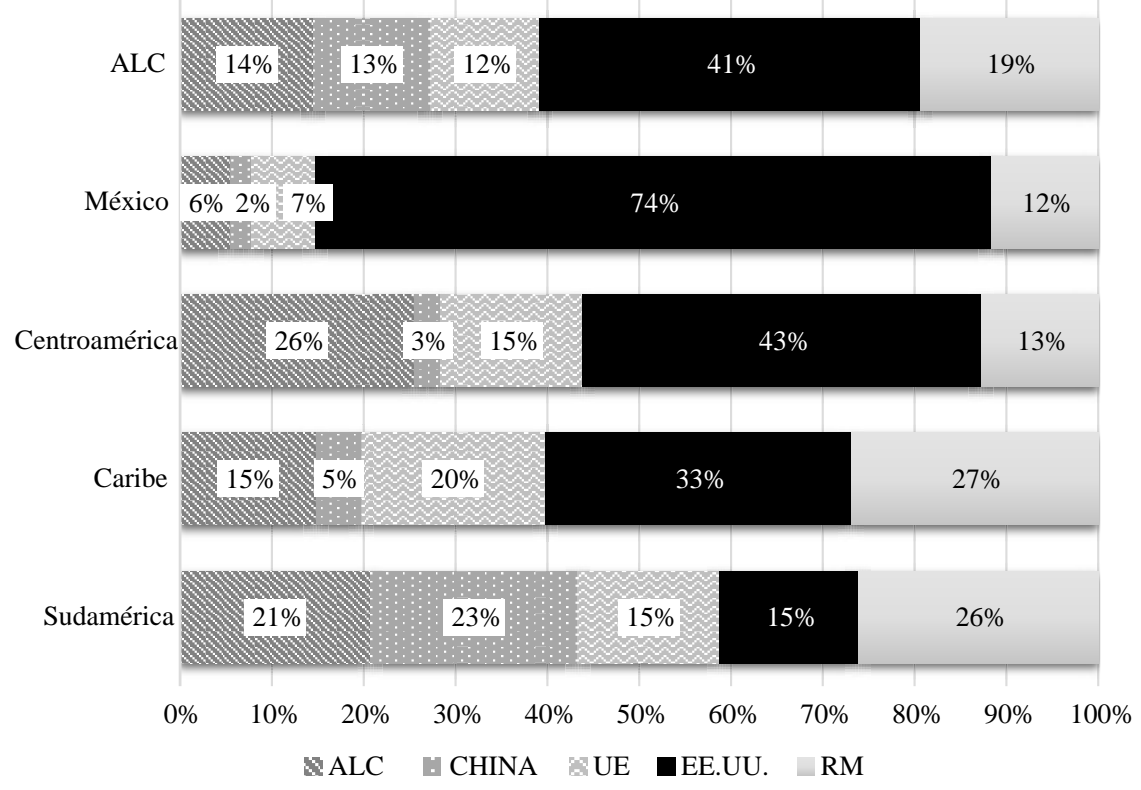

Fuente: elaboración propia con datos de BACI (CEPII).

China, primera economía afectada por el COVID-19, es destino de $13 \%$ de las exportaciones de ALC y en particular para Sudamérica es el principal socio comercial (23\%). En 2019, fue el único de los cuatro principales socios que expandió sus compras a la región (4.1\%). Sin embargo, el impacto de la crisis sanitaria ya se observó en los registros del primer bimestre del año, cuando las importaciones a ALC cayeron 4.2\% (gráfico 3). Por su parte, la dinámica del comercio con EE. UU., principal destino de las exportaciones de México y de la mayoría de los países de Centroamérica y el Caribe, ya se encontraba debilitada antes de que la pandemia afectara a esta economía, lo cual ocurrió a partir del mes de marzo. En 2019 las compras de la economía norteamericana a la región estuvieron estancadas, y en enero y febrero de 2020 se contrajeron $0.3 \%$ (gráfico 4). Cabe notar, además que, si se excluye a México, la caída del primer bimestre del año fue de $12.3 \%$. 
Gráfico 3. Exportaciones de ALC a China. Tasa de variación interanual, enerofebrero 2020 vs. enero-febrero 2019

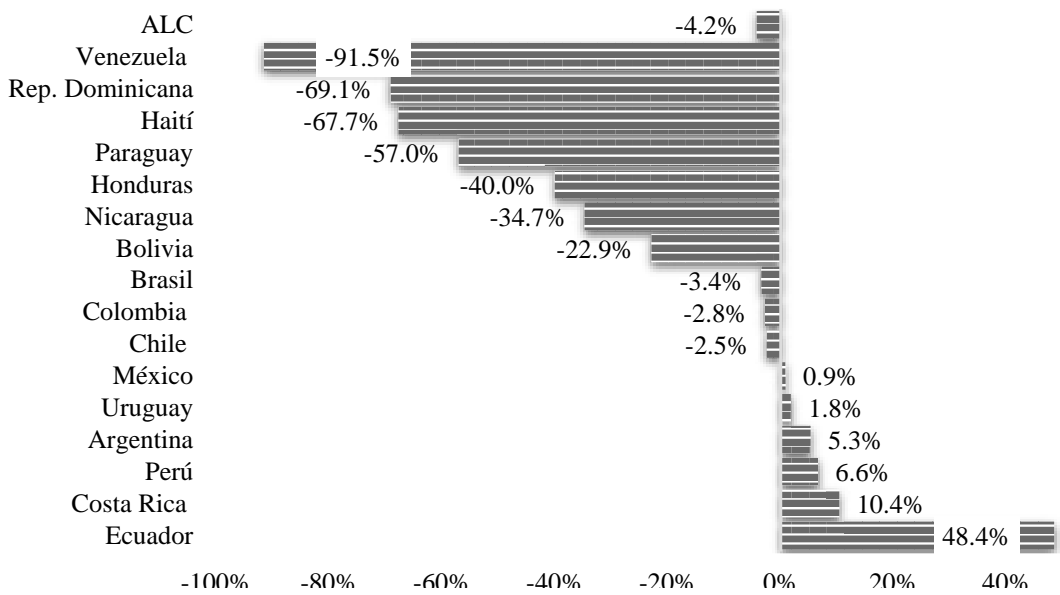

Fuente: elaboración propia con datos de MOFCOM.

Gráfico 4. Exportaciones de ALC a EE. UU. Tasa de variación interanual, enero-febrero 2020 vs. enero-febrero 2019

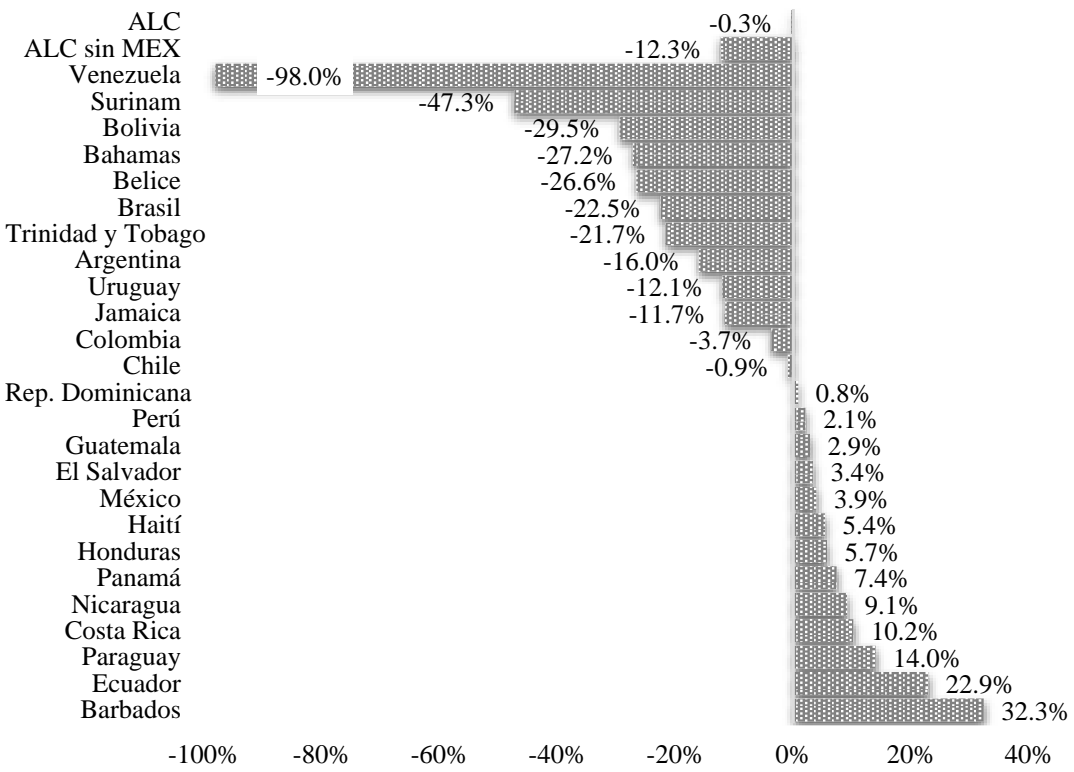

Fuente: elaboración propia con datos de United States Census Bureau. 
Por el lado de la oferta, el impacto para el comercio de ALC será consecuencia de la interrupción de las cadenas globales de valor, los obstáculos en la logística y los mayores controles en las fronteras y, por lo tanto, de menor provisión de insumos industriales. Algunas de las economías más afectadas serán México, Brasil y Argentina, que muestran alta dependencia de insumos importados para su industria automotriz, electrónica y farmacéutica, así como algunos de los países de Centroamérica en el sector textil (gráfico 8). El desabastecimiento impactará sobre su capacidad de producción que tendrá efectos colaterales tanto sobre su oferta interna como sobre sus exportaciones.

Gráfico 5. Incidencia de los productos básicos en las exportaciones totales de ALC. Porcentaje, 2018

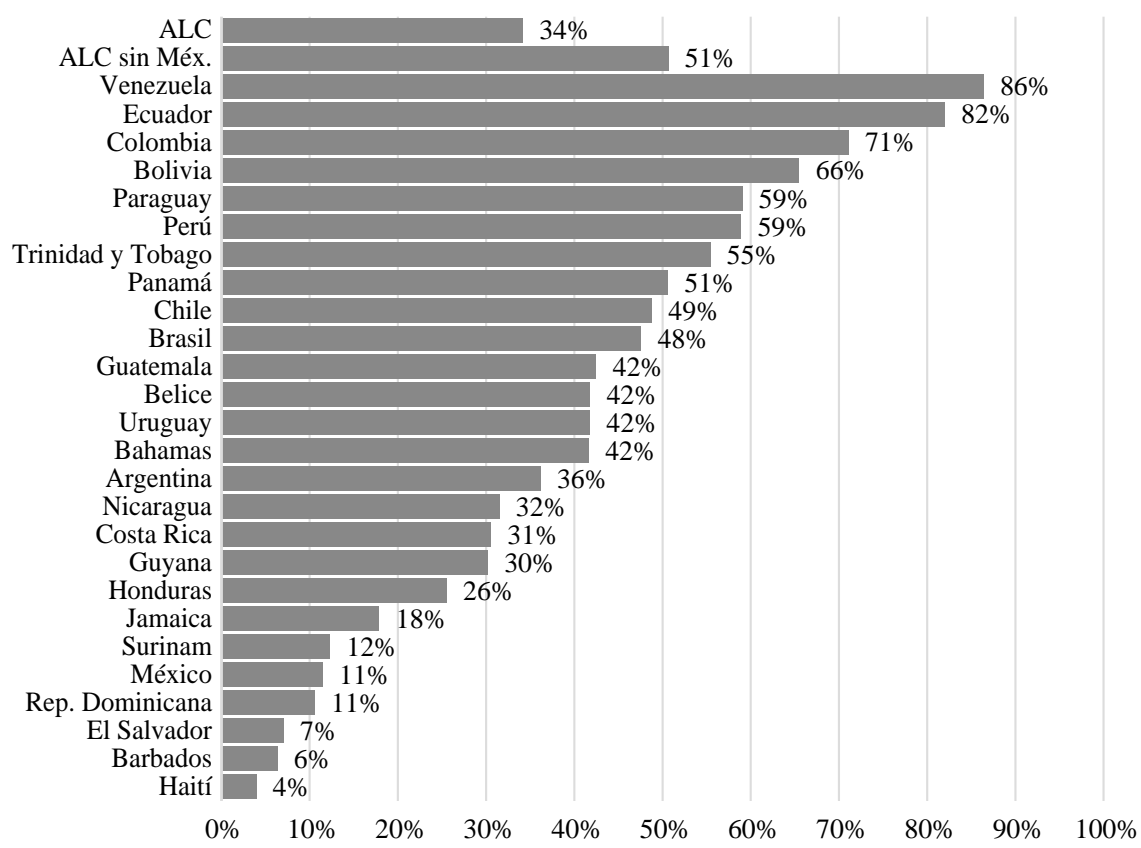

Fuente: elaboración propia con datos de BACI (CEPII).

Además de la escasa diversificación en términos de socios, las exportaciones de ALC se encuentran fuertemente concentradas en productos básicos. En 2018 el $34 \%$ de las ventas externas totales de ALC fueron productos básicos y el porcentaje asciende a 51\% si se excluye a México (gráfico 5). En 18 de los 26 países de ALC analizados, esta canasta representa más de $30 \%$ de sus exportaciones totales. Este 
aspecto del sector externo de la región expone la vulnerabilidad de los términos de intercambio a la alta volatilidad que muestran los precios de este tipo de bienes en los momentos de crisis. A modo de ejemplo, el petróleo, que representa alrededor de $10 \%$ de las exportaciones totales de la región, perdió $60 \%$ de su valor entre el 31 de diciembre de 2019 y el 18 de marzo de 2020; mientras que el precio del cobre y el azúcar cayeron alrededor de $20 \%$ en ese mismo período (gráfico 6).

Los servicios también se verán afectados por el shock en la demanda. En particular, el sector viajes fue el primero en sentir el impacto de las medidas para contener la expansión del virus, entre ellas, el bloqueo de fronteras, la disminución en la frecuencia de los vuelos y el cierre de hoteles, entre otras. Además, la recuperación no será inmediata una vez superada la crisis sanitaria, considerando la incertidumbre de la población con respecto a nuevos brotes. Este sector representa casi 50\% de las exportaciones de servicios de ALC y en algunos países del Caribe explica más de $80 \%$ y el aporte al PIB es de alrededor de 20\% (gráfico 7).

Gráfico 6. Precios de productos básicos de exportación de ALC. Tasa de variación, 18 de marzo de 2020 vs. 31 de diciembre de 2019

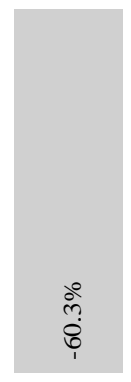

PETRÓLEO

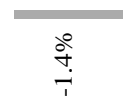

MINERAL

DE HIERRO

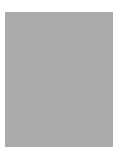

$\frac{d}{\text { Ni }}$

COBRE

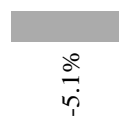

SOJA

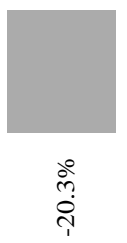

AZÚCAR

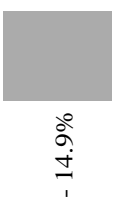

CAFÉ

Fuente: elaboración propia con datos de Bloomberg.

En este contexto de crisis sanitaria resulta difícil identificar oportunidades. Aunque existen, la posibilidad que estas compensen las pérdidas es casi nula. Entre los sectores exportadores que podrían aumentar su actividad, o al menos mantenerla, se encuentran en bienes: aquellos vinculados con insumos y equipamientos médicos, y en servicios, los empresariales o de informática, y sería un contexto positivo para el crecimiento de segmentos como telemedicina, educación a distancia o plataformas de teletrabajo. Sin embargo, estos sectores, en conjunto, representan menos de 30\% del total de las exportaciones de servicios ALC. Gráfico 7. Vulnerabilidad del sector 
turismo en América Latina y el Caribe. Participación del rubro viajes en exportaciones totales de servicios, 2018, y del gasto turístico receptor sobre el PIB, 2017

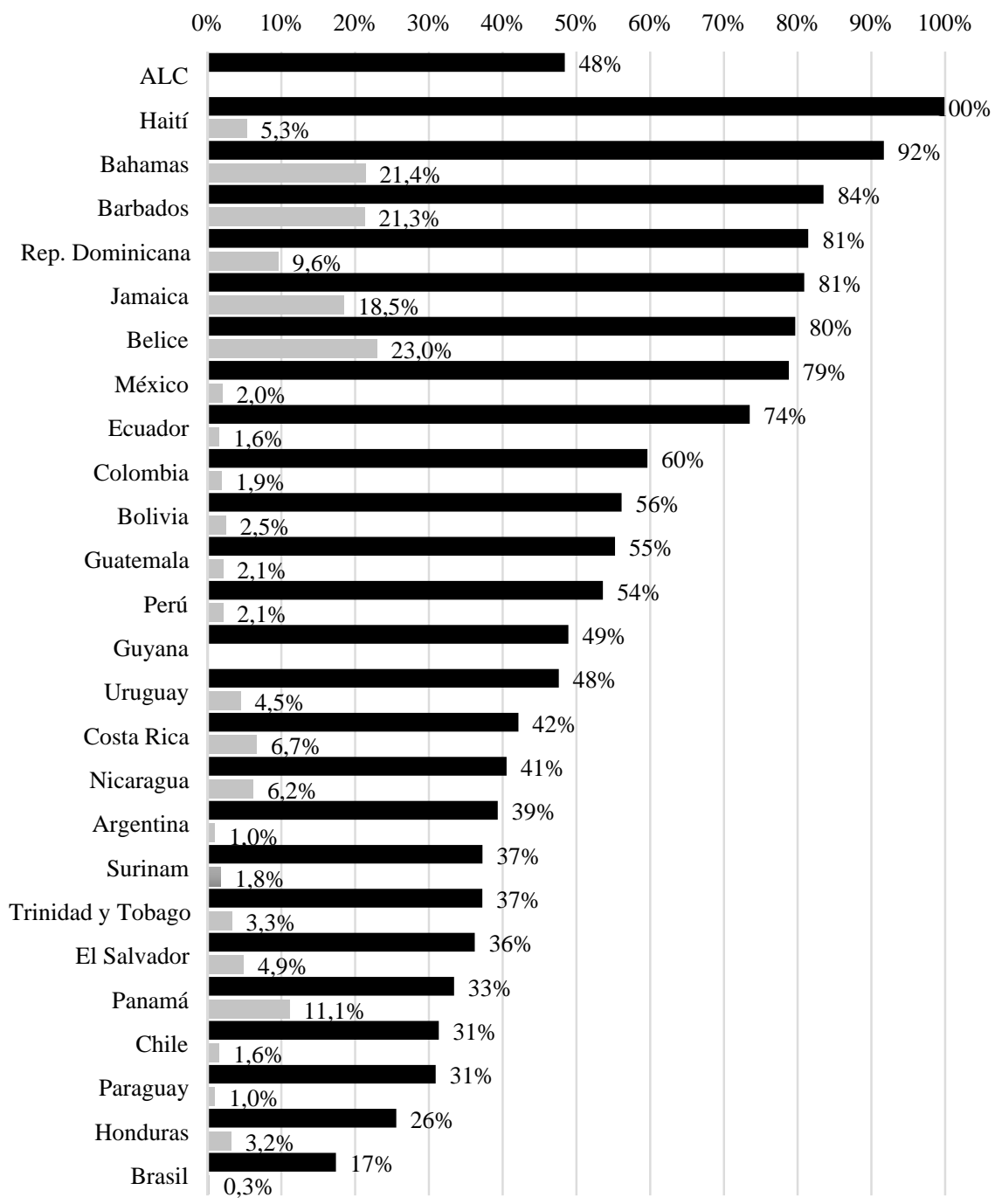

- \% viajes en exportaciones totales de servicios $\quad$ \% gasto turístico receptor sobre PIB

Fuente: elaboración propia con datos de fuentes nacionales, OMC y CEPAL. 
Gráfico 8. Incidencia de los bienes intermedios y componentes en las exportaciones totales de ALC. Porcentaje, 2018

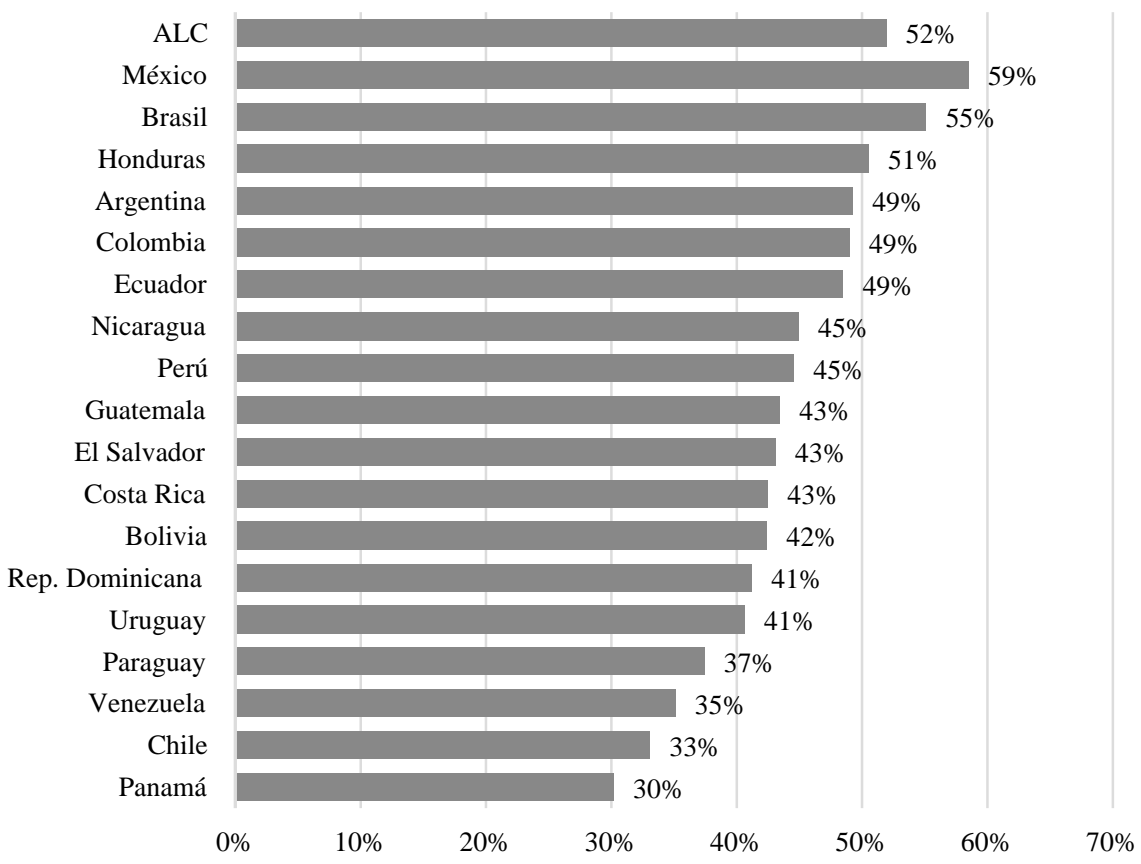

Fuente: elaboración propia con datos de INTradeBID.

\section{LAS MEDIDAS QUE AFECTAN AL COMERCIO}

La crisis sanitaria desatada por el COVID-19 ha dado lugar a la implementación de políticas comerciales en sectores estratégicos relacionados con la pandemia. En particular, la mayor cantidad de medidas aplicadas están vinculadas al comercio de insumos y equipamiento médico. Otro sector que ha sido foco de instrumentos comerciales es de alimentos. Casi todos los países de ALC, importadores netos de insumos médicos, adoptaron políticas para facilitar su ingreso, entre las que se destacan reducciones arancelarias, simplificación de trámites, suspensión de licencias de importación y de derechos antidumping (tabla 1). 
Sin embargo, estas políticas se han encontrado con respuestas por parte de las economías proveedoras de estos insumos. China, la UE y EE. UU. son responsables de casi dos tercios de las importaciones totales de este tipo de productos de ALC y en los tres se aplicaron medidas que podrían limitar su oferta (figura 1). En el caso de China, el 1 de abril anunció nuevas medidas de control para las empresas exportadoras de insumos médicos², mientras que en la UE las exportaciones fuera del bloque deben tener la aprobación previa del país miembro donde resida la empresa ${ }^{3}$, y EE. UU. restringió las exportaciones de insumos médicos clave invocando el Defense Production Act. ${ }^{4}$ Adicionalmente, según el Global Trade Alert más de 60 países han implementado políticas restrictivas al comercio de productos médicos 5 .

Tabla 1. Medidas aplicadas por los países de ALC con impacto sobre comercio de bienes

\begin{tabular}{|c|c|c|c|c|c|}
\hline \multirow[b]{2}{*}{ Países } & \multicolumn{3}{|c|}{ Medidas } & \multicolumn{2}{|c|}{ Sector } \\
\hline & $\begin{array}{l}\text { Eliminación } \\
\text { de licencias } \\
\text { y derechos } \\
\text { antidumping }\end{array}$ & $\begin{array}{l}\text { Eliminación de } \\
\text { aranceles }\end{array}$ & $\begin{array}{l}\text { Facilidad de } \\
\text { trámites de } \\
\text { importación }\end{array}$ & Alimentos & $\begin{array}{c}\text { Insumos y } \\
\text { equipamiento } \\
\text { médico y artículos } \\
\text { de higiene }\end{array}$ \\
\hline Argentina & SÍ & SÍ & - & SÍ & SÍ \\
\hline Brasil & Sí & Sí & - & SÍ & SÍ \\
\hline Chile & - & - & Sí & - & Sí \\
\hline Colombia & - & Sí & - & - & SÍ \\
\hline Ecuador & - & Sí & - & - & SÍ \\
\hline El Salvador & - & Sí & - & SÍ & Sí \\
\hline Guatemala & - & SÍ & SÍ & SÍ & SÍ \\
\hline Jamaica & - & Sí & - & - & SÍ \\
\hline Panamá & - & Sí & SÍ & - & SÍ \\
\hline Paraguay & - & SÍ & - & - & SÍ \\
\hline Perú & - & Sí & - & - & SÍ \\
\hline $\begin{array}{l}\text { Trinidad y } \\
\text { Tobago }\end{array}$ & - & - & SÍ* & SÍ & Sí \\
\hline
\end{tabular}

2 MOFCOM (2020).

3 Bown (2020).

4 Reuters (2020).

5 Evennet (2020). 


\begin{tabular}{cccccc}
\hline Uruguay & - & Sí & - & - & SÍ \\
\hline Venezuela & - & SÍ & - & sí & SÍ \\
\hline
\end{tabular}

Fuente: BID-INTAL (2020b).

Notas: *Acceso a divisas.

Figura 1. Principales proveedores de insumos y equipos médicos de ALC

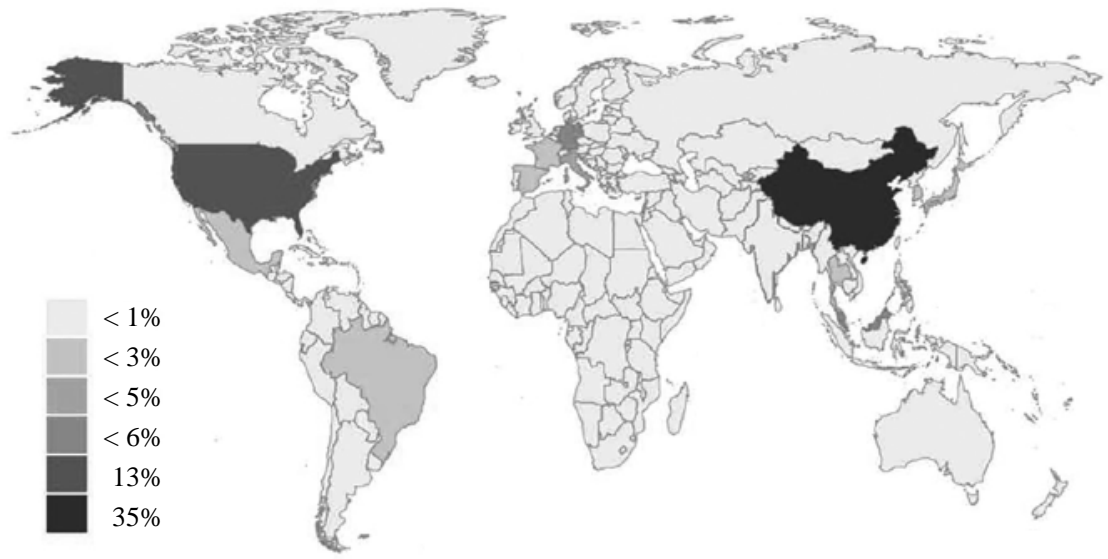

Fuente: BID-INTAL (2020b).

\section{CONCLUSIÓN}

El comercio internacional es uno de los canales de contagio económico de la crisis que está provocando la pandemia del COVID-19. En este aspecto, el sector externo de América Latina y el Caribe se verá afectado tanto por el lado de la demanda como de la oferta, así como por el impacto en los términos de intercambio. La retracción de la demanda externa de sus principales socios, China, la UE y EE. UU., hasta ahora las economías más afectadas por el virus, profundizará el ya deslucido desempeño que las exportaciones de la región han mostrado en los últimos años. Adicionalmente, la alta concentración de las ventas externas de ALC en productos básicos aumenta la vulnerabilidad a la fuerte variaciones en sus precios. Finalmente, la oferta también se verá afectada por las disrupciones en las cadenas globales de valor como resultado de los problemas logísticos y los mayores controles de frontera. Las medidas comerciales que están adoptando los países de 
ALC para facilitar el comercio de algunos productos médicos y alimentos podrán compensar solo parte del impacto negativo del comercio, y además se enfrentan con políticas restrictivas por parte de algunos de los principales proveedores a nivel global.

\section{REFERENCIAS BIBLIOGRÁFICAS}

BID-INTAL. (2020a). Impacto del COVID-19 en el comercio exterior, las inversiones y la integración en América Latina y el Caribe. Newsletter n. ${ }^{0}$ 1, 27 de marzo. Recuperado de http://conexionintal.iadb.org/2020/03/25/newsletter/?utm_source=Espa\%C3\%B1ol\&utm_campaign=20ecf23b45-EMAIL_ CAMPAIGN_2017_11_09_COPY_01\&utm_medium=email\&utm_ term=0_a729517049-20ecf23b45-161112097

BID-INTAL. (2020b). Impacto del COVID-19 en el comercio exterior, las inversiones y la integración en América Latina y el Caribe. Newsletter n. ${ }^{\circ}$ 2, 8 de abril.

Bown, C. (2020). EU limits on medical gear exports put poor countries and Europeans at risk. 19 de marzo, Trade and investment policy watch. Peterson Institute for international economics. Recuperado de https://www.piie.com/ blogs/trade-and-investment-policy-watch/eu-limits-medical-gear-exportsput-poor-countries-and

Evenett, S. (2020). Tackling covid-19 together the trade policy dimension. Global Trade Alert team, University of St. Gallen, Switzerland. 23 de marzo. Recuperado de https://www.wita.org/atp-research/tackling-covid-19-together-the-trade-policy-dimension/

Giordano, P. (2020). ¿Cuán expuesta está América Latina al contagio comercial del coronavirus? 27 de marzo. [Blog Más allá de las fronteras. BID Sector de Integración y Comercio]. Recuperado de https://blogs.iadb.org/integracioncomercio/es/america-latina-contagio-comercial-coronavirus/

Williamson, C. (2019). PMI signals further near-stalling of global manufacturing at start of second quarter. 7 de mayo. IHS Markit. Recuperado de https:// ihsmarkit.com/research-analysis/pmi-signals-near-stalling-of-global-manuat-start-of-second-quarter-070519.html

MOFCOM. (2020). Anuncio No. 5 de 2020 de la Administración General de Aduanas del Ministerio de Comercio de la República Popular de China sobre la exportación de materiales médicos en orden. 31 de marzo. Recuperado de http://www.mofcom.gov.cn/article/b/e/202003/20200302950371.shtml

Opertti, F. (2020). Impacto del coronavirus en el comercio y la integración: ¿qué hacer? 24 de marzo. [Blog Más allá de las fronteras. BID Sector de Inte- 
gración y Comercio]. Recuperado de https://blogs.iadb.org/integracioncomercio/es/coronavirus-comercio-integracion/

Reuters. (2020). Trump invokes Defense Production Act to stop export of masks. 3 de abril. Business News. Recuperado de https://www.reuters.com/article/ us-health-coronavirus-usa-memo/trump-invokes-defense-production-actto-stop-export-of-masks-idUSKBN21M00E

(C) 2020 por los autores; licencia no exclusiva otorgada a la revista Estudios económicos. Este artículo es de acceso abierto y distribuido bajo los términos y condiciones de una licencia Atribución-No Comercial 4.0 Internacional (CC BY-NC 4.0) de Creative Commons. Para ver una copia de esta licencia, visite http:// creativecommons.org/licenses/by-nc/4.0 